\title{
Article
}

\section{Study on Overturn Proof Monitoring System of Mobile Crane}

\author{
Bok-Joong Yoon ${ }^{1}$, Kil-Soo Lee ${ }^{1}$ and Jae-Hak Lee ${ }^{2, *}$ \\ 1 Convergence Machinery Research Lab., Korea Construction Equipment Technology Institute, \\ Gunsan-si 54004, Jeollabuk-do, Korea; bjyoon@koceti.re.kr (B.-J.Y.); kslee@koceti.re.kr (K.-S.L.) \\ 2 Department of Aeronautical \& Mechanical Engineering, Changshin University, \\ Changwon-si 52833, Gyeongsangnam-do, Korea \\ * Correspondence: jhleepaul@cs.ac.kr; Tel.: +82-55-250-1352
}

Citation: Yoon, B.-J.; Lee, K.-S.; Lee, J.-H. Study on Overturn Proof Monitoring System of Mobile Crane. Appl. Sci. 2021, 11, 6819. https:// doi.org/10.3390/app11156819

Academic Editor:

Amadeo Benavent-Climent

Received: 1 July 2021

Accepted: 22 July 2021

Published: 24 July 2021

Publisher's Note: MDPI stays neutral with regard to jurisdictional claims in published maps and institutional affiliations.

Copyright: (c) 2021 by the authors. Licensee MDPI, Basel, Switzerland. This article is an open access article distributed under the terms and conditions of the Creative Commons Attribution (CC BY) license (https:// creativecommons.org/licenses/by/ $4.0 /)$.

\begin{abstract}
While up-right build structures are under construction, an over-hung crane has a major role in efficient lifting and transporting heavy materials from one point to another. There are several types of cranes for a variety of construction sites, such as bridge/overhead, barge lift, tower crane, etc. The mobile crane is one of the most widely used types of construction equipment due to its mobility. Unfortunately, the number of crane accidents including casualties and deaths has increased over the last decade. In order to reduce these fatal tragedies, a dynamic simulator of mobile cranes based on analyzed overturn limit data has been developed and analysis results have been applied to site tests. The test bench is formulated to simulate the actual construction field and some practical experiments have been performed in realistic manners of operation. Moreover, wireless network communication systems are applied for monitoring the status of the crane from a distance where visibility is not secure. Consequently, the applicability in the field derived from operating the simulator and actual vehicle testing confirmed the feasibility of applying it to construction sites.
\end{abstract}

Keywords: mobile crane; anti-overturn; zero moment point; monitoring system

\section{Introduction}

While up-right build structures are under construction, an over-hung crane has a major role in efficient lifting and transporting heavy materials from one point to another. There are several types of crane in various construction sites, such as bridge/overhead, barge lift, tower crane, etc. The mobile crane is one of the most widely used types of construction equipment due to its mobility. The mobile crane is a system equipped with a crane on a commercial vehicle for general crane functions. Recently, large-sized and highpowered cranes are required according to the size of the construction site [1]. The increase in architectural scale occurs in high altitude operations with heavy materials. Moreover, lifting and holding materials in harsh conditions such as strong winds, heavy rain and ground vibration has catastrophic consequences on the safety of operators [2]. M.F. Milazzo et al. (2016) reported that mobile cranes account for approximately $72 \%$ of accidents during the entire construction period [3]. Mobile cranes are prescribed to prevent accidents as a type of heavy lifter in "Article 132 of the Rules for Occupational Safety and Health" in South Korea. Nevertheless, the number of crane accidents including casualties and death have increased over the last decade [4]. Much research on the safety of tower [5,6] and bridge cranes $[7,8]$ have been performed worldwide [9]. The major causes of mobile crane accidents are overturning (45\%) due to structural failure [10] of the outrigger, collapse of ground and overloading. Overloading could be well addressed through obeying procedure and following regulations [11].

In this paper, a dynamic simulator of mobile cranes based on analyzed overturn limit data from zero moment point (ZMP) theory $[12,13]$ has been developed and analysis results were applied to site tests. The test bench was composed of an actual construction field and the practical experiments were performed in a realistic manner of operation. Moreover, 
wireless network communication systems [14] were applied for monitoring the status of the crane from a distance where visibility was not secure. Consequently, the applicability to the field from operating the simulator and actual vehicle tests, confirmed the feasibility of application to the construction site.

\section{A Simulator of Mobile Crane}

\subsection{Zero Moment Point Theory}

In order to develop the dynamic simulator of mobile cranes, numerical analysis of turnover felling limit had to be produced. The limit data analysis has been derived from zero moment ZMP theory of mass systems for position vector P [15]. Equation (1) and the parameters of the equations are listed in Table 1; assuming that the ZMP for the vehicle could be written as Equation (2); the ZMP for acceleration and rotation velocity to determine the overturning can be rewritten as Equation (3); assuming that the moment and external force are not applied Equation (3) could be expressed as Equation (4).

Table 1. Description of variables.

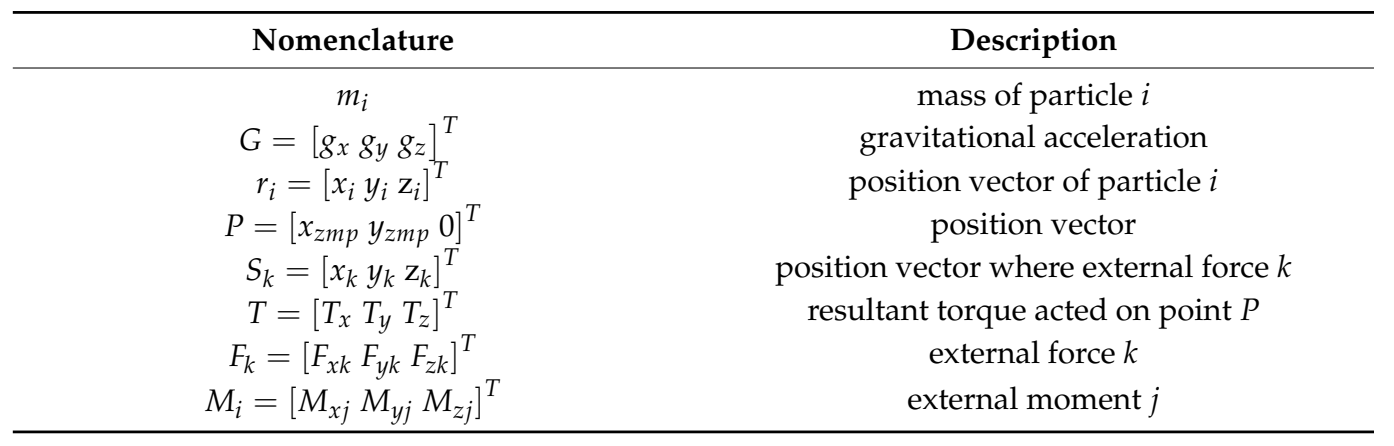

$$
\begin{gathered}
\sum_{i} m_{i}\left(r_{i}-P\right) \cdot\left\{\left(\frac{d^{2} r_{i}}{d t^{2}}+G\right)-\frac{d^{2} P}{d t^{2}}\right\}+T-\sum_{i} M_{i}-\sum_{k}\left(S_{k}-P\right) \cdot F_{k}=0 \\
x_{z m p}=\frac{\sum_{i} m_{i}\left(\ddot{z}_{i}+g_{z}\right) x_{i}-\sum_{i} m_{i}\left(\ddot{x}_{i}+g_{z}\right) z_{i}+\sum_{i}\left(S_{z k} F_{x k}-S_{x k} F_{z k}\right)}{\sum_{i} m_{i}\left(\ddot{z}_{i}+g_{z}\right)-\sum_{i} F_{z k}} \\
y_{z m p}=\frac{\sum_{i} m_{i}\left(\ddot{z}_{i}+g_{z}\right) y_{i}-\sum_{i} m_{i}\left(\ddot{y}_{i}+g_{z}\right) z_{i}+\sum_{i}\left(S_{y k} F_{z k}-S_{z k} F_{y k}\right)}{\sum_{i} m_{i}\left(\ddot{z}_{i}+g_{z}\right)-\sum_{i} F_{z k}} \\
x_{z m p}=\frac{\sum_{i} m_{i} g_{z} x_{i}-\sum_{i} m_{i} g_{z} z_{i}+m a h}{\sum_{i} m_{i} g_{z}}=\frac{\sum_{i} m_{i} g_{z} x_{i}-\sum_{i} m_{i} g_{z} z_{i}}{\sum_{i} m_{i} g_{z}}+\frac{a}{g_{z}} h \\
y_{z m p}=\frac{\sum_{i} m_{i} g_{z} y_{i}-\sum_{i} m_{i} g_{z} z_{i}+m v \omega h}{\sum_{i} m_{i} g_{z}}=\frac{\sum_{i} m_{i} g_{z} x_{i}-\sum_{i} m_{i} g_{z} z_{i}}{\sum_{i} m_{i} g_{z}}+\frac{v \omega}{g_{z}} h \\
x_{z m p, n o f o r c e}=\frac{\sum_{i} m_{i}\left(\ddot{z}_{i}+g_{z}\right) x_{i}-\sum_{i} m_{i} \ddot{x}_{i} z_{i}}{\sum_{i} m_{i}\left(\ddot{z}_{i}+g_{z}\right)} \\
y_{z m p, n o f o r c e}=\frac{\sum_{i} m_{i}\left(\bar{z}_{i}+g_{z}\right) y_{i}-\sum_{i} m_{i} \ddot{y}_{y^{\prime}} z_{i}}{\sum_{i} m_{i}\left(\ddot{z}_{i}+g_{z}\right)}
\end{gathered}
$$

In order to determine the overturning stability from ZMP theory a stable area has to be established. In the case of caterpillar excavators, the rectangular area set as a stable area was formed by the length and width of the caterpillar. With typical construction equipment whose operation requires the unfolding of the outrigger, such as with mobile cranes, the rectangular area formed by the front and rear outrigger is distributed, allowing for a stable area as shown in Figure 1. 


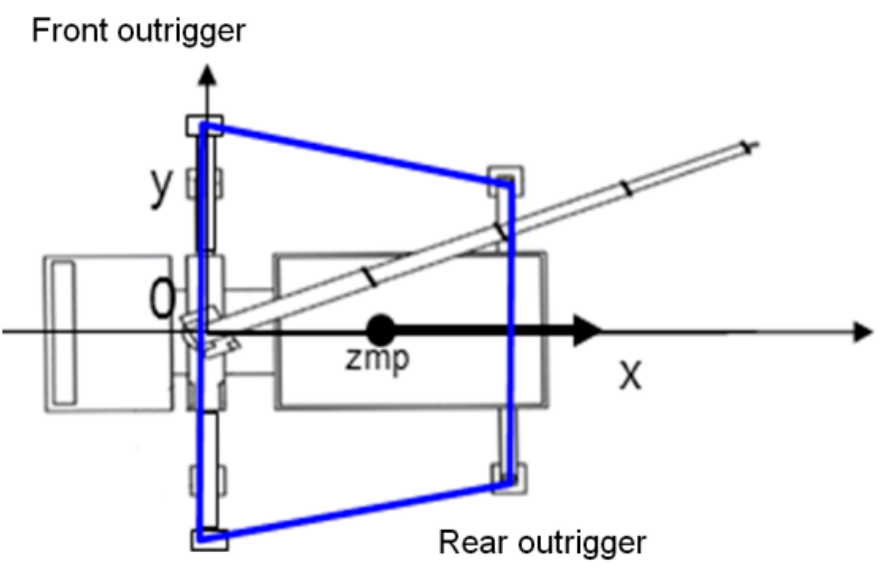

Figure 1. Schematic diagram of the stable area of a mobile crane.

\subsection{Overturn Securing Algorithm}

The $x$ and $y$ components of the ZMP could be calculated by the mass (weight), center of gravity position and gravitational acceleration component as shown in Equation (4). Based on this information, the ZMP is derived from classifying the fixed vehicle body and the variable part of the boom and load. Moreover, the ZMP requires reference coordinates as location information. The point initiates where the center of the pivot axis of the boom meets the ground and is set as the reference coordinate system; the boom coordinate system is set to the center of the first axis of rotation of the boom, for convenience of calculation. The process of anti-overturn securing algorithms is shown in Figure 2.

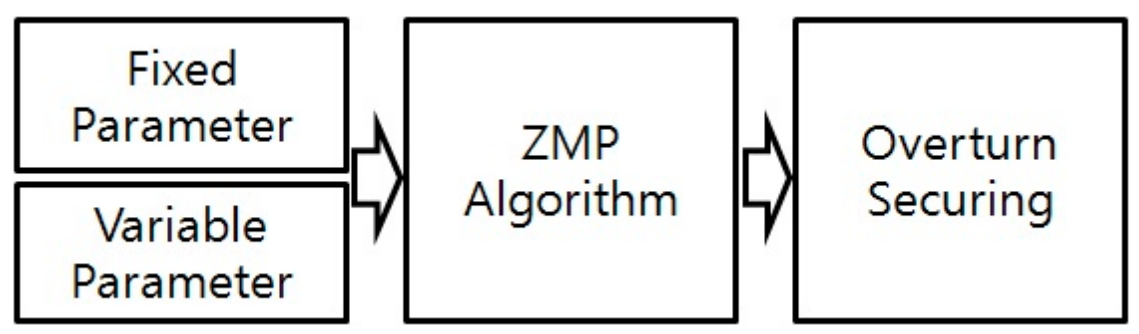

Figure 2. The process of anti-overturn securing algorithms.

The 20-ton-class mobile crane manufactured was 3D modeled and composed of major components such as columns, rotation plates, sub-frames, outriggers and tires as shown in Figure 3. The 3D modeling performed various movements, such as withdrawal, intakes and ascending, descending from column parts, etc.; the design also included pivoting with the rotation plate. 


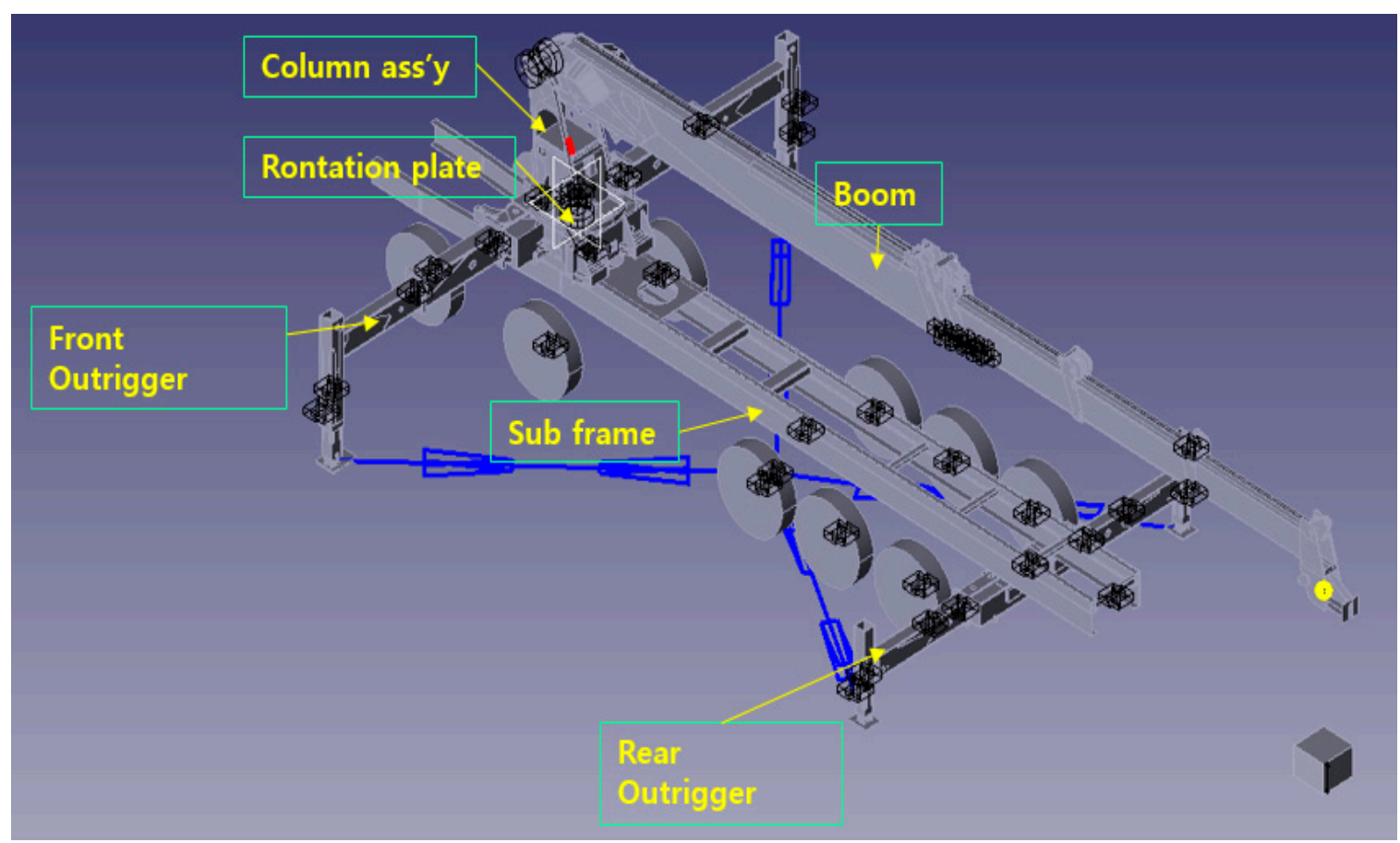

Figure 3. 3D Modeling of mobile crane (Model No. SS7506).

\subsection{Dynamic Characteristic Analysis}

In order to investigate dynamic characteristics, actual parameters such as weight, length, relief angle, working radius and outrigger length of the crane are reflected in the analysis. The dynamic analysis was applied to the movement of the boom's turning, ascending and descending (center of gravity change). The outrigger reaction force value, which is the support point, was derived and analyzed. Moreover, crane operation was simulated considering the constraint, contact and load conditions and the result was derived for the entire crane model through dynamic analysis.

The limit of overturning has been analyzed according to the working radius of the crane through dynamic simulation. The simulation was performed to find a situation where the undulation angle was fixed at $0^{\circ}$ and the boom length was adjusted (work radius change) to invert when a limit load was applied at each work radius. The total analysis time was $45 \mathrm{~s}$ and a simulation was performed sequentially, turning 90 degrees from the rear to the lateral direction (counterclockwise) and then descending from a maximum angle of 78 to 0 degrees. At this time, the total length of the boom was $21.6 \mathrm{~m}$ and the loading weight was set to 4 tons.

As for the results of the analysis from Figure 4, the graph confirmed that the size of the reaction force was almost the same in all four positions of the front and rear outriggers due to the large body weight of 26 tons compared to the 3 tons load weight. The load weight is insignificant, so the magnitude of the four-point reaction force is not significantly different. As the analysis progressed, the rear outrigger reaction force gradually increased while the external force increased and the loading weight increased, while the front outrigger reaction force decreased; the overturning load was reached when the front outrigger reaction force became $0 \mathrm{~N}$. The side overturning from load weight 48,070 N simulation is shown in Figure 5 . 

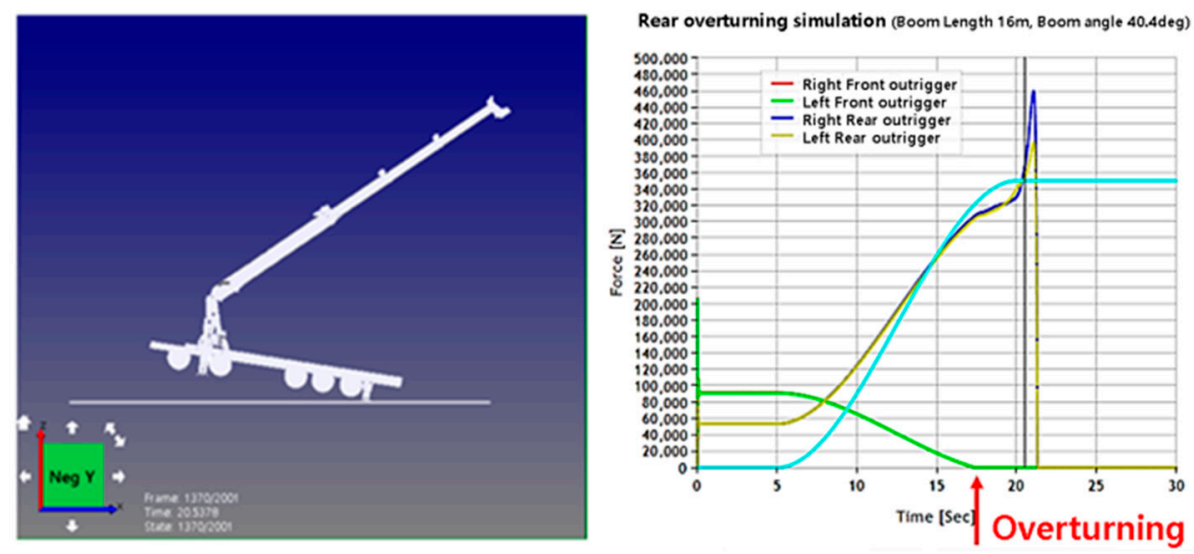

Figure 4. The simulation result of rear overturning.
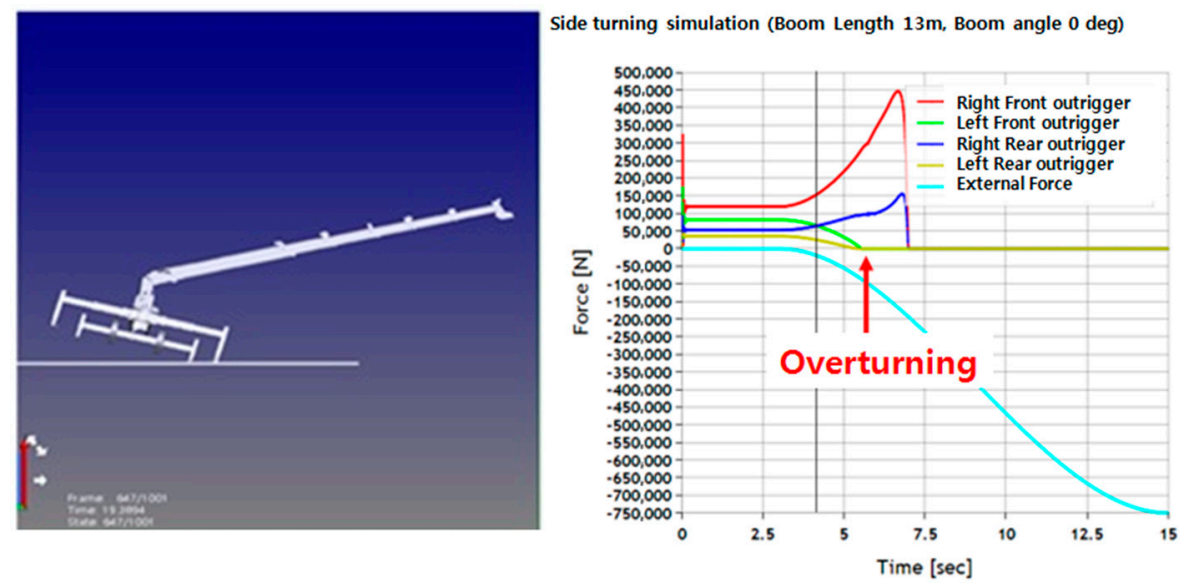

Figure 5. The simulation result of side overturning.

Table 2 shows the result of the reaction forces of the outrigger. The result confirmed that the larger the working radius, the smaller the felling load size in addition to the inversely related relationship with the felling moment value and the working radius. Table 2 summarizes the size of the initial outrigger reaction forces.

Table 2. Analyzed results of outrigger reaction forces.

\begin{tabular}{cccc}
\hline Operation Radius (m) & Overturn Load (kN) & $\begin{array}{c}\text { Initial Reaction } \\
\text { Force Front } \\
\text { Outrigger (kN) }\end{array}$ & $\begin{array}{c}\text { Initial Reaction } \\
\text { Force Rear Outrigger } \\
\mathbf{( k N )}\end{array}$ \\
\hline 13 & 227 & 79.8 & 79.5 \\
16 & 171 & 72.5 & 86.8 \\
19 & 122.5 & 65.1 & 94.1 \\
\hline
\end{tabular}

Prior to the actual vehicle experiment, optimization considering the weight of the crane cabin and attachments was performed to compare the simulated values of the four outrigger points and the measured values at the points installed on the ground. While calibrating the simulation model based on the value of the outrigger reaction force, the error rate between the measured value of each outrigger and the analyzed value for each outrigger position was calculated to be $1.7 \%, 3.9 \%, 7.7 \%, 7.6 \%$ and the result was consistent with the measured value as shown in Table 3. 
Table 3. Comparison between the simulation result and actual load of reaction force.

\begin{tabular}{ccccc}
\hline Reaction Forces $\mathbf{( k g}_{\mathbf{f}} \mathbf{)}$ & Right Front & Left Front & Right Rear & Right Rear \\
\hline simulation & 7916 & 7961 & 4908 & 4913 \\
actual loads & 8120 & 8290 & 5320 & 5320 \\
\hline
\end{tabular}

Since the center of gravity of the body of the crane modeling is almost similar to the actual crane, it was possible to develop a simulation model similar to the actual vehicle through optimal arrangement of auxiliary parts.

\section{Performance Evaluation and Field Test}

The mobile crane control program was developed and applied before the actual test and the crane safety program is shown in Figure 6. The system was designed from the ZMP algorithm through Visual Studio 2015 MFC and included the configuration of fixed and variable parameters, the displaying of ZMP results, overturn securing ratio and prediction and warning signals. Moreover, the remaining distance to the felling point, two-stage alarm display and safety display function for each turning angle were added and the maximum lifting load and safety factor was calculated.

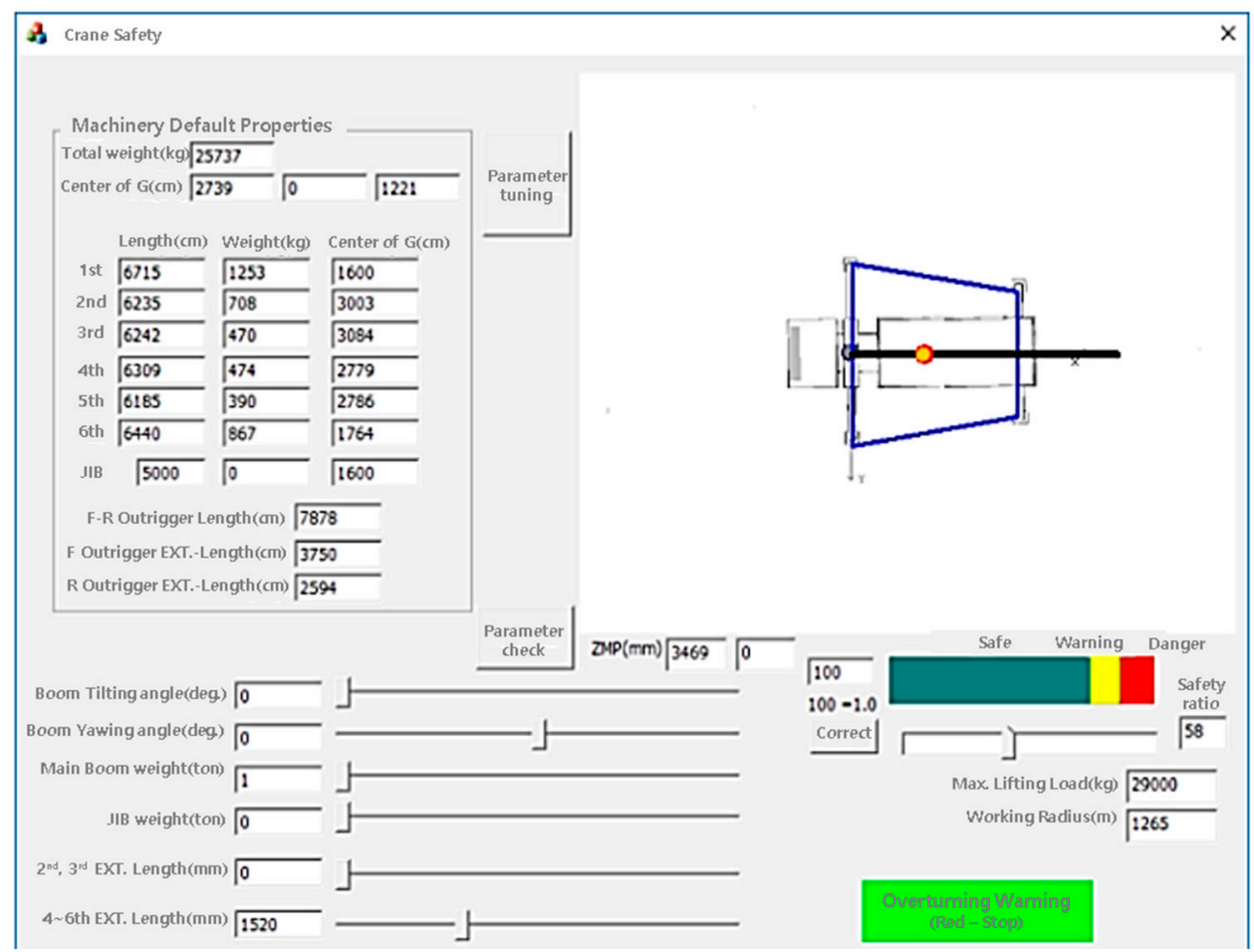

Figure 6. The mobile crane control program UI.

In order to find the overturn limit of mobile cranes, the felling condition was determined according to the current state of the crane by using the load change applied to the four outriggers supporting the crane. The crane extends the four outriggers to $0 \sim 25 \mathrm{~m}$ according to the experimental conditions and locates the axle underneath as shown in Figure 7 (a sensor for measuring the load applied to the outrigger) and then lifts the crane by lowering the outrigger. 


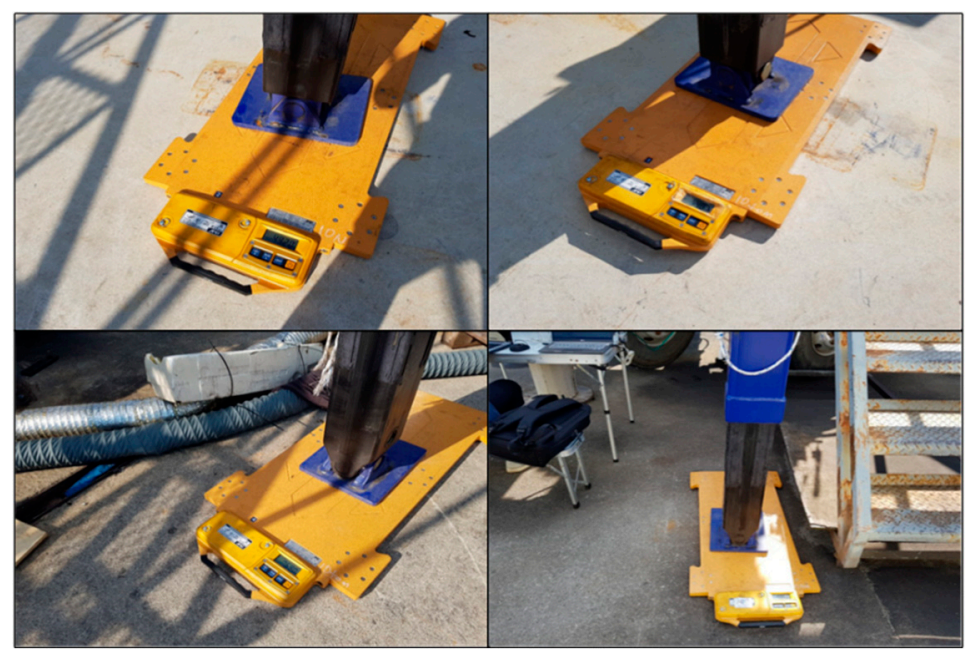

Figure 7. The outrigger axle installation in actual field test.

After positioning, the crane performs work according to various experimental conditions from the initial state and simultaneously monitors the reaction force of the outrigger and the state of the crane through the monitoring program as shown in Figure 8.

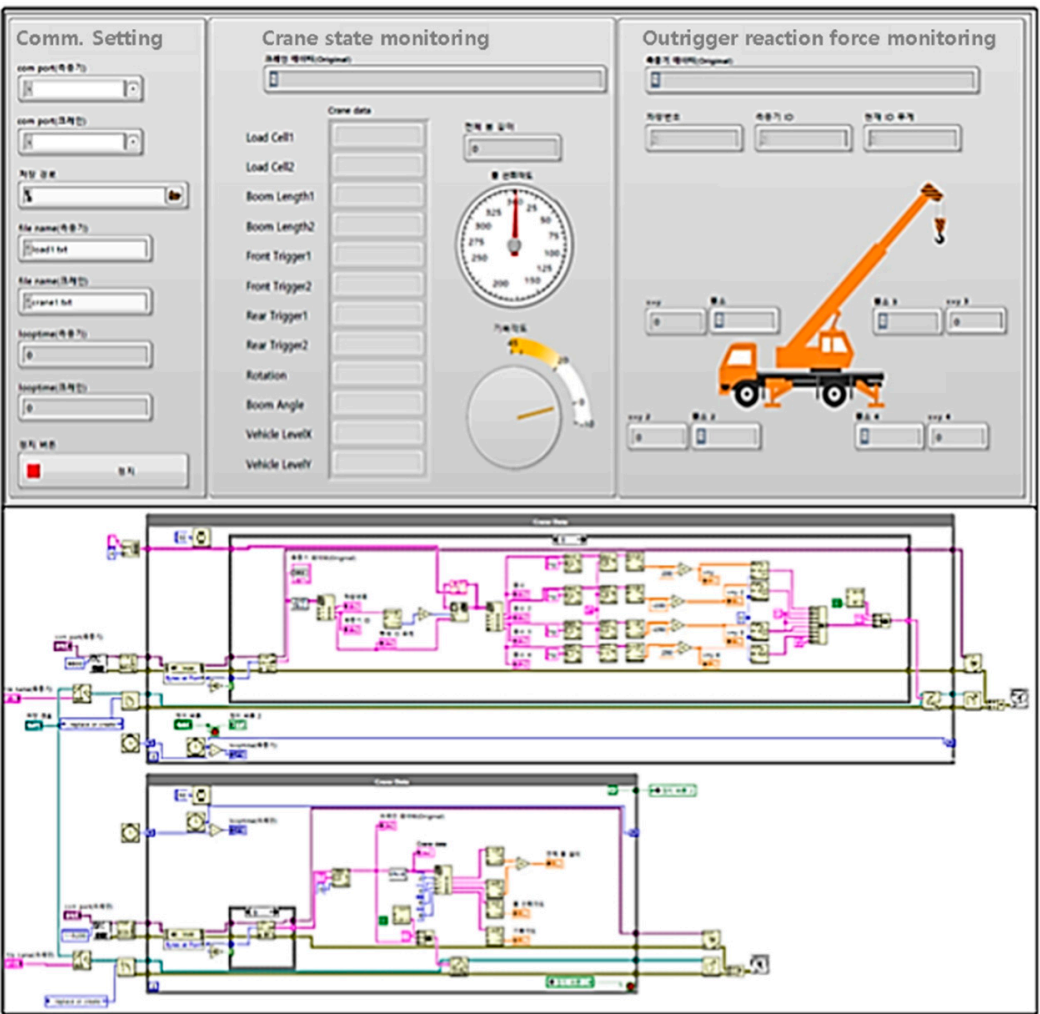

Figure 8. The real time monitoring system of mobile crane.

The system was developed in a PC environment, connected to two USB ports using serial to USB gender and developed a program using NI Labview. Crane data was programmed to receive 12 data separated by line feed constants. The crane axle was configured to receive and display 4 individual crane data from its own indicator. The displayed value is the sum of the total weight and is displayed on the indicator. Using the monitoring program, we observed the change in reaction force measured in the axle according to the movement of the crane as shown in Figure 9. 


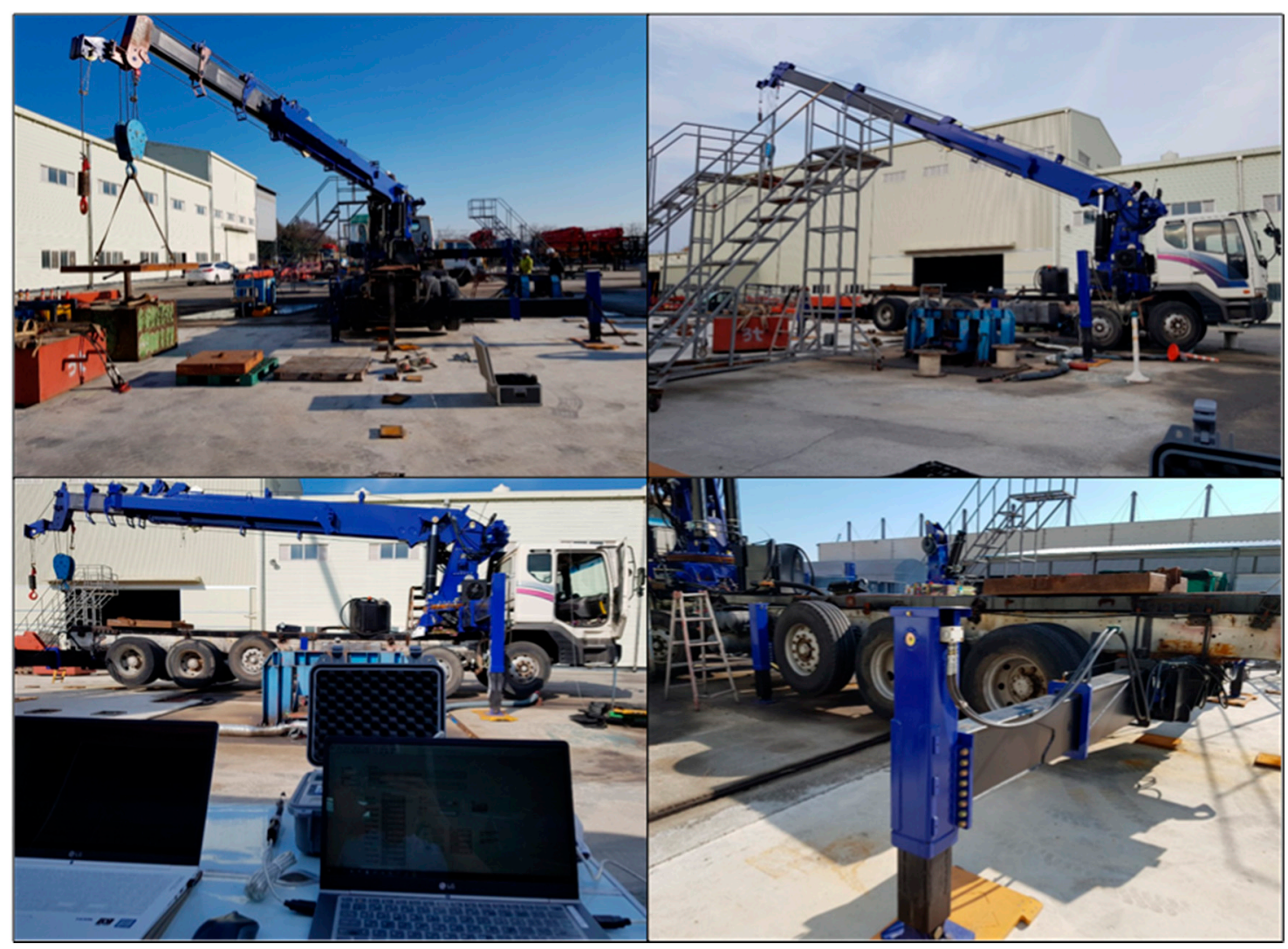

Figure 9. Measuring the reaction force of mobile crane.

Each outrigger's reaction force result and actual vehicle operation data from attached sensors were equipped with a dual-core $\mathrm{CPU}$ or higher to support the appropriate transmission rate of the Android-based OS. The transmission to the control server, 3G or 4G (LTE) communication was used and the Internet of Things (IoT) communication module was adapted to reduce the cost of transmission. Bluetooth 4.0 or higher was used for communication between the terminal and the display, a G-mouse type external GPS module installed inside the terminal was applied to collect location information. Moreover, a temperature sensor and an impact sensor were additionally installed to detect the impact of temperature and impact on the terminal during operation. Lastly, the housing was manufactured based on the theory of mechanism design to satisfying the grade of IP66 (International Protection ratings).

The data was stored in accordance with various case experiment scenarios and compared the results with dynamic analysis. The crane measured and stored the amount of reaction force change of the axle crane in real time according to changes in boom length, swing and undulation angle and compared it with dynamic analysis results (moments) and showed a match rate of up to $95 \%$. Figure 10 shows the result of the load changes of the crane according to the boom length. 


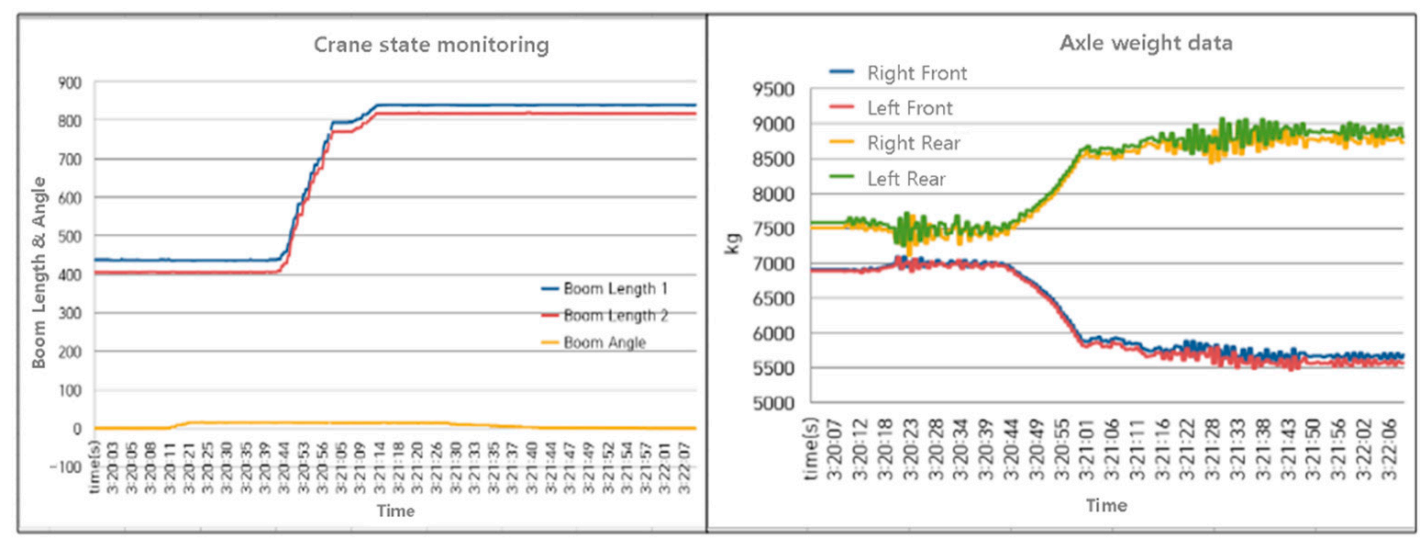

Figure 10. The result of the axel loads according to changes boom length.

The data was stored to various experiment scenarios which compared the results via dynamic analysis. The crane measures and stores the amount of reaction force change to the axle crane in real time according to changes in boom length, swing and undulation angle and compares it with dynamic analysis results (moments), showing a match rate of up to $95 \%$. Figure 10 shows the result of the load changes to the crane according to the boom length.

Utilizing the monitoring program developed, the reaction force changes were measured on the axis mid-term relative to the motion of the crane and stored according to the test scenario. The data for comparison of results to the dynamic analysis results are shown in Table 4.

Table 4. Comparison between the simulation result and actual load of reaction force.

\begin{tabular}{ccccc}
\hline Reaction Forces $\left.\mathbf{~}_{\mathbf{k g}} \mathbf{f}\right)$ & $\mathbf{7 . 7}(\mathbf{m})$ & $\mathbf{1 3} \mathbf{( m )}$ & Lift 2 Tons \\
\hline \multirow{3}{*}{ simulation } & 1 & 8090 & 7160 & 6890 \\
& 2 & 8180 & 7320 & 6910 \\
& 3 & 5280 & 6180 & 7510 \\
actual loads & 4 & 5320 & 6230 & 7580 \\
& 1 & 8240 & 1630 & 7059 \\
& 2 & 8256 & 1645 & 7065 \\
error $(\%)$ & 3 & 5188 & 8489 & 7405 \\
& 4 & 5188 & 5745 & 7390 \\
\hline \multirow{3}{*}{} & 1 & 1.8 & 4.5 & 2.4 \\
& 2 & 0.9 & 3.4 & 2.2 \\
& 3 & 2.4 & 4.8 & 1.3 \\
\hline
\end{tabular}

Table 4 compares the reaction force and analysis value of the outrigger point, which is the basic condition of the crane boom length at $7.7 \mathrm{~m}$ and after lifting the boom $13 \mathrm{~m}$, it lifts 2 tons of heavy weight and compares the actual measured value with the analysis value. Point 1 is the right front outrigger, 2 is the left front outrigger, 3 is the right rear outrigger and 4 is the left rear trigger axle weight value.

\section{Conclusions}

The mobile crane is one of the most widely used cranes and accounts for approximately $72 \%$ of accidents during the construction with the crane. The major causes of mobile crane accident are overturning $(45 \%)$, structural failure of the outrigger, collapse of the ground and overloading. In order to reduce the number of crane accidents, an anti-overturn securing Monitor System is suggested, a dynamic simulator of mobile cranes based on analyzed overturn limit data was developed and analysis of the results was applied to the site test. The test bench was formulated to simulate the actual construction field and some 
practical experiments were performed in the realistic manner of operation. The overturning limit was determined based on the ZMP position in the set stable area and the stability of the mobile from dynamic characteristic results or the crane was displayed on the terminal through the axle installed in four places. The applicability in the field was confirmed using the simulation result values according to the overturning limit and then the adequate test was carried out to determine the feasibility of the designed simulator to the construction site. The result from actual field tests was performed using the movement test during the actual construction and various crane operations. Moreover, an Internet of Things (IoT) communication module was adapted to transmit to the control server and Bluetooth 4.0 was used for communication between the terminal and the display.

Author Contributions: Data curation, K.-S.L.; Formal analysis, J.-H.L.; Investigation, B.-J.Y. and K.-S.L.; Project administration, B.-J.Y.; Supervision, J.-H.L.; Validation, B.-J.Y.; Visualization, K.-S.L.; Writing-original draft, J.-H.L.; Writing-review and editing, J.-H.L. All authors have read and agreed to the published version of the manuscript.

Funding: This work was supported by Changshin University Research Fund of 2021-037.

Institutional Review Board Statement: Not applicable.

Informed Consent Statement: Not applicable.

Conflicts of Interest: The authors declare no conflict of interest.

\section{References}

1. Irizarry, J.; Karan, E. Optimizing Location of Tower Cranes on Construction Sites through GIS and BIM Integration. J. Inf. Technol. Constr. (ITcon) 2012, 17, 351-366.

2. Shapira, A.; Lyachin, B. Identification and Analysis of Factors Affecting Safety on Construction Sites with Tower Cranes. J. Constr. Eng. Manag. 2009, 135, 24-33. [CrossRef]

3. Milazzo, M.F.; Ancione, G.; Spasojević-Brkić, V.; Valis, D. Investigation of crane operation safety by analysing main accident causes. Risk Reliab. Saf. Innov. Theory Pract. 2016, 74-80.

4. Yu, Y.H. Forensic investigation on crane accidents. Int. J. Forensic Eng. 2017, 3, 319. [CrossRef]

5. Tran, Q.H.; Huh, J.; Doan, N.S.; Mac, V.H.; Ahn, J.-H. Fragility Assessment of a Container Crane under Seismic Excitation Considering Uplift and Derailment Behavior. Appl. Sci. 2019, 9, 4660. [CrossRef]

6. Ko, S.-H.; Lee, K.-H.; Lee, C.-H. Safety Verification of Gantry Cranes using Hydraulic Cylinders. J. Drive Control. 2019, 16, 8-14.

7. Ma, X.; Bao, H. An Anti-Swing Closed-Loop Control Strategy for Overhead Cranes. Appl. Sci. 2018, 8, 1463. [CrossRef]

8. Xiao, R.; Wang, Z.; Guo, N.; Wu, Y.; Shen, J.; Chen, Z. Multi-Objective Motion Control Optimization for the Bridge Crane System. Appl. Sci. 2018, 8, 473. [CrossRef]

9. Gharaie, E.; Lingard, H.; Cooke, T. Causes of fatal accidents involving cranes in the Australian construction industry. Constr. Econ. Build. 2015, 15, 1-12. [CrossRef]

10. Khodadadian, A.; Noii, N.; Parvizi, M.; Abbaszadeh, M.; Wick, T.; Heitzinger, C. Bayesian estimation method for variational phase-field fracture problems. Comput. Mech. 2020, 66, 827-849. [CrossRef] [PubMed]

11. Brecher, C.; Japer, D.; Fey, M. Analysis of New, Energy-Efficient Hydraulic Unit for Machine Tools. Int. Précis. Eng. Manuf.-Green Technol. 2017, 4, 5-11. [CrossRef]

12. Um, H.; Choi, J.; Kim, S.; Yang, S.; Lee, J. A Study on Reversal Stability of Hydraulic Excavator for Crane Work. Trans. Korean Soc. Mach. Tool Eng. 2004, 13, 64-72.

13. Ghasempoor, A.; Sepehri, N. A Measure of Stability for Mobile Manipulators with Application to Heavy-Duty Hydraulic Machines. J. Dyn. Sys. Meas. Control. 1998, 120, 360-370. [CrossRef]

14. Yoon, B.-J.; Lee, K.-S.; Lee, J.-H. A Novel Predictable Rock Breaker Using Intelligent Hydraulic Control with ICT Convergences. Appl. Sci. 2019, 9, 3333. [CrossRef]

15. Nadar, M.A.; Awakian, C.A.; Khoury, H.K. An intelligent system for monitoring tower crane on construction site. In Proceedings of the 30th ISARC, Montréal, QC, Canada, 11-15 August 2013; pp. 1239-1246. 